\title{
Türk Tekstil İşletmelerinin Endüstri 4.0’a Adaptasyonunun İncelenmesi
}

\section{An Investigation of the Adaptation of Turkish Textile Enterprises to Industry 4.0}

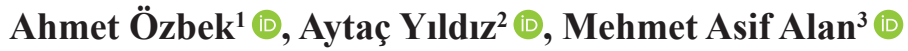

${ }^{1}$ (Doç. Dr.), Marmara Üniversitesi, Teknoloji Fakültesi, Tekstil Mühendisliği Bölümü, İstanbul, Türkiye

${ }^{2}$ (Doç. Dr.), Bursa Teknik Üniversitesi,

Mühendislik ve Doğa Bilimleri Fakültesi,

Endüstri Mühendisliği Bölümü, Bursa, Türkiye

${ }^{3}$ (Doktora Öğrencisi), Bayburt Üniversitesi, Fen

Bilimleri Enstitüsü, Bayburt, Türkiye

ORCID: A.Ö. 0000-0001-5015-8082;

A.Y. 0000-0002-0729-633X;

M.A.A. 0000-0002-6947-404X

\section{Corresponding author:}

Aytaç YILDIZ

Bursa Teknik Üniversitesi, Mühendislik ve Doğa

Bilimleri Fakültesi, Endüstri Mühendisliğ

Bölümü, Bursa, Türkiye

E-mail address: aytac.yildiz@btu.edu.tr

Submitted: 06.04 .2021

Revision Requested: 06.07.2021

Last Revision Received: 08.07.2021

Accepted: 06.10.2021

Citation: Ozbek, A., Yildiz, A. ve Alan, M. A. (2021). Türk tekstil işletmelerinin endüstri 4.0'a adaptasyonunun incelenmesi. Acta Infologica, $5(2), 255-265$.

https://doi.org/10.26650/acin.910774

\section{ÖZ}

Endüstri 4.0, uzun zamandır hakim olan insan odaklı üretim anlayışını kökten değiştirerek insanı üretimden büyük oranda dışlamak üzerine kurulu yeni bir üretim anlayışıdır. Bu anlayış her geçen gün yaygınlaşmakta olup geleceğin üretim anlayışı olacağı tahmin edilmektedir. Bu nedenle bu anlayışa adaptasyonun, işletmelerin gelecekteki başarılarında belirleyici faktörlerden birisi olacağı öngörülmektedir. Bu çalışmada, Türkiye'de faaliyet gösteren tekstil işletmelerinin Endüstri 4.0'a adaptasyonunun incelenmesi amaçlanmıştır. Çalışma kapsamında tekstil işletmelerinin endüstri 4.0'a bakış açısını ve kullandıkları endüstri 4.0 teknolojilerinden beklentilerini analiz etmek için bir anket hazırlanmıştır. İlgili anket İstanbul Sanayi Odası'nın (İSO) 500 büyük işletme sıralamasına 2018 yılında girmeyi başarmış 67 tekstil işletmesine uygulanmış ve elde edilen veriler analiz edilmiştir. Analiz sonuçlarına göre; işletmelerin en fazla kullandıkları teknolojinin ERP olduğu, yatırım maliyetinin yüksekliği nedeniyle işletmelerin sadece yarısının endüstri 4.0 teknolojilerine yatırım yaptığı, endüstri 4.0'ın tekstil sektörüne uygulanabilir olduğu inancının olduğu, verimlilik artışı sağlamak ve maliyetleri düşürmek için bu teknolojilere yatırım yapıldığı ve sonuç olarak da en afazla verimlilikte artışının sağlandığı tespit edilmiştir.

Anahtar kelimeler: Endüstri 4.0, Tekstil Sektörü, Endüstri 4.0 Teknolojileri

\section{ABSTRACT}

Industry 4.0 is a new understanding of production and is based (to a great extent) on the removal of people from production by radically changing the understanding of people-oriented production - a concept that has dominated for a long time. This understanding is becoming more widespread day by day and it is predicted that the future will mean a better understanding of production. Therefore, it is anticipated that adaptation to this understanding will be one of the determining factors in the future success of enterprises. In this study, it was aimed to investigate the adaptation of textile companies operating in Turkey to Industry 4.0. Within the scope of the study, a questionnaire was prepared to analyze the perspectives of textile companies towards industry 4.0 and their expectations from the industry 4.0 technologies they use. The questionnaire was applied to 67 textile companies that ranked in the top 500 large enterprises of the Istanbul Chamber of Industry (ISO) in 2017 and 2018 and the data obtained were analyzed. According to the results of the analysis it was determined that the technology that businesses use the most is ERP. Due to the high investment cost, it has been determined that only half of enterprises invest in industry 4.0 technologies, that they believe that industry 4.0 is applicable in the textile industry, that to invest in these technologies will increase productivity and reduce costs, and as a result, the highest increase in efficiency will be achieved.

Keywords: Industry 4.0, Textile Industry, Industry 4.0 Technologies 


\section{GÍRİ̧̧}

Gelişmiş ülkeler 2000'lerde, üretimin gelişmekte olan Asya ülkelerine kaymasını önemli bir sorun olduğunun farkına varmışlardır. Bu sorunun çözümünün ise fiziksel ve sanal imalat sistemlerinin küresel anlamda birbirine bağlanarak oluşturulacak olan esnek bir işbirliğinden geçtiğini tespit ederek bu çözüme de Endüstri 4.0 adını vermişlerdir (Schwab, 2017). Endüstri 4.0 en dar anlamıyla, karmaşık fiziksel makine ve cihazların sensörler ile ağa ve birbirine bağlanması şeklinde tanımlanabilir (Mrugalska ve Wyrwicka, 2017). Daha geniş anlamda ise, "akıllı makinelerin, ürünlerin ve üretim kaynaklarının esnek üretim sistemlerine dikey entegrasyonu sağlanarak; farklı ölçütler bazında optimize edilebilecek sektörler arası değer ağlarına yatay entegrasyonu sağlanarak dünya çapındaki işletmelere önemli bir model şeklinde hizmet vermesidir” şeklinde tanımlanmaktadır (Kagermann, Anderl, Gausemeier, Schuh ve Wahlster, 2016). Endüstri 4.0; arz, üretim, bakım, teslimat ve müşteri hizmetlerinin tümünün internet üzerinden birbirine entegrasyonuna odaklanmaktadır (IEC, 2015). Bu entegrasyon, birbirine bağlı akıllı makinelerin, depolama sistemleri ve üretim kaynaklarının bağımsız olarak bilgi alışverişinde bulunabilmesine, eylemleri tetikleyebilmesine ve birbirlerini özerk olarak kontrol edebilmesini sağlamaktadır (Kagermann ve ark., 2016).

Endüstri 4.0'ın temellerini Şekil 1'de gösterilen teknolojiler olan; Eklemeli Üretim (3 Boyutlu -3D- Yazıc1lar), Nesnelerin İnterneti (IoT), Sanal Gerçeklik (Virtual Reality - VR), Siber Güvenlik (Cyber Security - CS), Büyük Veri (Big Data - BD), Otonom Robotlar, Bulut Bilişim Sistemi (Cloud Computing - CC) ve Simülasyon teknolojileri oluşturmaktadır (ATSO, 2017; Bulut ve Akçacı, 2017; Schwab, 2017; Xu, Xu, Li, 2018; Yıldız, 2018; Ozbek ve Yıldız, 2020).

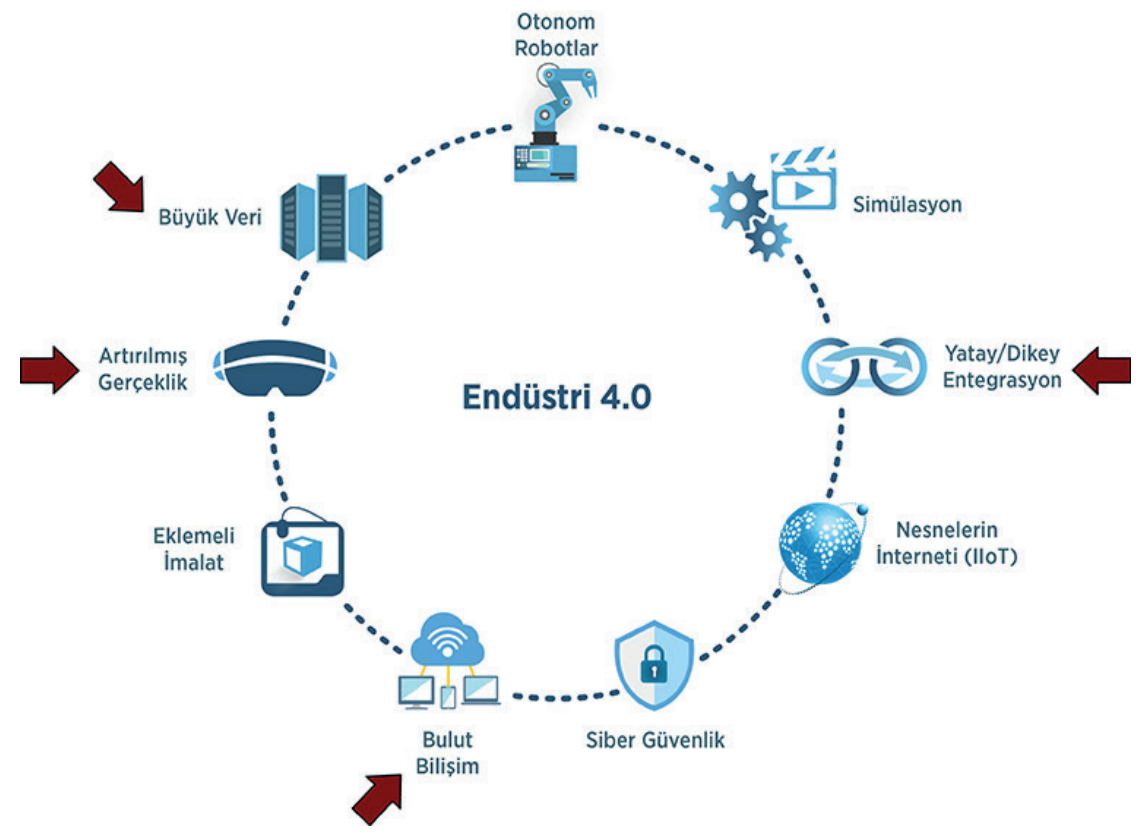

Şekil 1. Endüstri 4.0’’n Arkasındaki Teknolojiler (Melanson, 2018)

Almanya'da Endüstri 4.0 için kurulan ilk çalışma ekibinde yer alan Kagermann, Endüstri 4.0'1 uygulayan işletmelerin; verimliliklerinin artacağı (üretimde kaynak verimliliği \%30-40 artış), üretimde yüksek düzeyde esneklik kazanacakları, seri ürettikleri ürünlerin fiyata göre bireyselleştirebilme yeteneği kazanacakları böylece de küresel pazarlardaki şoklara dayanma kabiliyetlerinin artacağını ifade etmiştir (Kagermann, 2015). Ayrıca yapılan çalışmalara göre, işletmelerin; inovatif ürün ve hizmetler üretmek ve hızlı bir şekilde uygulamak, üretim maliyetini azaltmak, verimliliğini artırmak, büyümek, işgücü yapısını değiştirmek ve rekabet gücünü geliştirmek için Endüstri 4.0 teknolojilerini kullanmak zorunda kalacakları öngörülmüştür (Chen ve Xing, 2015; Kagermann ve ark., 2016; Hillard, 2017).

Bu çalışmada, Türk Tekstil sektöründe faaliyet gösteren işletmelerin Endüstri 4.0’a olan bakış açıları, yatırım yapma durumları, endüstri 4.0 teknolojilerini kullanım amaçları ve elde ettikleri sonuçların analiz edilmesi amaçlanmıştır. Çalışmanın bundan 
sonraki bölümünde tekstil endüstrisinde endüstri 4.0 teknolojilerinin kullanımı, 3. bölümde çalışmanın uygulama kısmına ve son bölümde de sonuç ve değerlendirmelere yer verilmiştir.

\section{TEKSTIL ENDÜSTRISINNDE ENDÜSTRİ 4.0 TEKNOLOJILERININN KULLANIMI}

Endüstri 4.0 teknolojileri, tekstil endüstrisinde kullanılmaya başlanmış olup tekstil endüstrisini derinden etkilemeye ve değiştirmeye devam etmektedir. İlgili teknolojilerden IoT’un tekstil endüstrisinde kullanılmasıyla birlikte, giysilere sensörler entegre edilmeye başlanmıştır. Sensörler vasıtasıyla hastaların hayati fonksiyonlarını (kalp atış hızı, sıcaklık, nefes alma, stres, hareket, hızlanma ve hatta hormon seviyeleri gibi) ve yürüyüş anormalliklerini gerçek zamanlı olarak ölçülüp verileri ak1llı telefon yoluyla doktorlara gönderebilen akıllı giysilerin üretilmesi mümkün hale gelmiştir (Awazade, 2017; FernándezCaramés ve Fraga-Lamas, 2018; Abtahi ve ark., 2018). Ayrıca yine IoT sayesinde uyumak üzere olan sürücüleri uyandıran araba koltukları, kalp atışlarını dinleyen yatak çarşafları gibi akıllı tekstillerin yaygınlığı her geçen gün artmaktadır (EBSO, 2017).

VR teknolojisinin tekstil endüstrisinde kullanılmasıyla, tekstillerin dokunsal algılanması (haptex) sağlanmıştır. Böylece kullanıcılar sanal tekstillere gerçek zamanlı olarak dokunmalarını sağlayan bir VR sistemi geliştirilmiştir (MagnenatThalmann ve Bonanni, 2006). Sanal gerçekçiliğin tekstil endüstrisinde kullanımının daha gelişmiş uygulaması, 3D sanal gerçeklik teknolojisinin dokuma kumaş tasarımı ve analizinde kullanılmaya başlanması olmuştur (Adanur ve Vakalapudi, 2013). Öyle ki 3D baskı teknolojisiyle; kesme, montaj ve dikiş tek bir adımda birleştirilerek üretim süreci kısaltılmış, kitlesel üretimden tasarıma dayalı kişisel üretime geçiş ve model sınırlaması olmadan üretim mümkün hale gelmiştir (Valtas ve Sun, 2016). VR sistemleri, eğitimin gerçek bir ortamda yapılamasının mümkün olmadığı ve hatta tehlikeli olabildiği durumlarda sıklıkla kullanılmaktadır (Allerkamp, 2010). Örneğin, tekstil malzemelerinin etkin şekilde görselleştirilmesi (Mikolanda, Lomov, Kosek ve Verpoest, 2004) tekstil malzemelerinin mekanik davranışını etkileyen iç mimarisi (deforme olabilirlik, drapaj, geçirgenlik vs.) ve tekstil kompozitlerinin özelliklerini (sertlik, mukavemet vb.) göstermek için sanal gerçeklik teknolojisinden yararlanılmaktadır (Lomov, Mikolanda, Kosek ve Verpoest, 2007). Ayrıca, VR teknolojileri örme makinesinde, ürün veya desen değişikliğinde, üretim hataları meydana geldiğinde müdahale edilmesi gereken durumlarda makine operatörünü destekleyecek sistem olarak kullanılmaktadır (Simonis, Gloy ve Gries, 2016). Diğer taraftan VR, bir tablet veya akıllı telefon aracılığıyla halı, SpinTales kilimi ve yorganlar üzerindeki belirli işaretleri tarayarak karakterleri görüntüleyebilmeye olanak sağlayarak çocukların eğlenceli zaman geçirmelerine imkân sağlamaktadır (Şehgal, 2017).

BD, hacimli verileri analiz ederek değerli bilgileri çıkarma işlemidir (Jain, Bruniaux, Zeng ve Bruniaux, 2017). Büyük verinin tekstil endüstrisinde kullanımına kadar, tekstil endüstrisinde talebini tahmin etmek için; uzmanlar, odak gruplar ve örnek verilerden yararlanmışlardır. Fakat bu yöntemde potansiyel ve gerçek müşterilerden veri toplamak ve analiz etmek için zaman alıcı ve yüksek maliyetliydi (Insights, 2018). Endüstri 4.0 teknolojileri, makineler arasında veri toplanmasını ve analiz edilmesini mümkün kılarak, düşük maliyetle daha kaliteli veriler elde edilmesini sağlamaktadır. Bu verilerin üretimde kullanılmasıyla daha hızlı, daha esnek ve daha verimli üretim mümkün hale gelmiştir. Ayrıca bu veriler aracılığıyla işletmelerin, üretimin gelecekte hangi yöne gideceğini ve müşteri memnuniyeti konusunda ne yaparlarsa başarılı olacaklarını belirlemeleri daha kolaylaşacaktır. Örneğin, moda dünyasında, büyük veriler artan bir şekilde trend tahmininde, tüketici davranışlarını, tercihlerini ve duygularını analiz etmede kullanılmaya başlanmıştır (Jain ve ark., 2017).

Robotik sistemler merkezi bir sunucuya, veri tabanına veya programlanabilir mantık denetleyicisine bağlı olarak bir aktivasyonu herhangi bir insan müdahalesine gerek kalmadan gerçekleştirebilen, koordine edebilen ve otomatik hale getirebilen sistemlerdir (Amoroso ve Tamburrini, 2019). Robotik sistemler kendilerine verilen görevleri akıllıca, en az insan girdisiyle ve düzenli bir şekilde gerçekleştirilebilmektedir. Robotik sistemler malzemeleri taşımakta, engellerden kaçınmakta, diğer robotik sistemlerle koordineli çalışabilmektedir. Ayrıca teslimatların gerçek zamanlı olarak nerede gerekli olduğunu tespit edebilmektedirler (Melanson, 2018). Robotik sistemlerin tekstil endüstrisinde kullanımı işçilik maliyetlerini ve hata oranlarını azaltarak tekstil endüstrisinde önemli değişikliklere neden olacaktır. Örneğin, Akıllı Üretim Yönetim Sistemleri (Intelligent Production Management Systems) makine ve teçhizatların çalışma bilgilerine sahiptir. Böylece makinelerin çalışma durumunda bir sorun olduğunda görüntülü izleme sisteminden aldığı komut sayesinde 3D model ve onarım kılavuzu komutu alıp onarımı 
gerçekleştirmekte veya makine üreticisine bakım çağrısı yaparak makine bakım sistemini hayata geçirebilmektedir (Chen ve Xing, 2015).

3D yazıcı teknolojileri, bilgisayar tarafından gönderilen verileri gerçek nesnelere dönüştürmekle kalmayıp tüketicileri de üreticiye dönüştüren teknolojilerdir (EBSO, 2017). Bu teknolojilerden 3D yazıcılar, yazılım komutları ile tasarım dosyasını eşleştirir ve ardından ürünün üretimini parçalar halinde gerçekleştirirler. Daha sonra ise üretilen parçalar, yapıştırma, eritme ve kanca dikiş gibi montajlama yöntemleriyle birleştirilirler. 3D yazıcılarla üretim yönteminde parçaların bağımsız olarak üretilmesi, tekstil ve modadaki geleneksel üretimin esnek olmama dezavantajından kaçınılarak gelişmelere ve/ya değişimi yakalamak kolaylaşmaktadır. Ayrıca kesme, montaj ve dikiş gibi işlem adımları tek bir adımda birleştirilerek üretim süreci kısaltılarak maliyet, zaman ve iş gücü gibi birçok avantaj elde edilmektedir. 3D yazıcılarla üretimin diğer avantajları ise; insan kaynaklı dikiş hataları ortadan kaldırılarak üretim kalitesini artırmak, kumaşların tam ölçülere göre üretilmesini sağlayarak kumaş atıklarını ortadan kaldırarak maliyet ve çevre açısından avantaj sağlamaktadır, kitlesel üretimden tasarıma dayalı kişisel üretime geçişi kolaylaştırarak model sınırlaması olmadan üretim imkânı sağlar (Valtas ve Sun, 2016). 3D yazıcılarının tekstil sektöründeki önemli uygulamalarından birisi de çok katmanlı kumaşların üretilmesinde kullanılmasıdır (Adanur ve Vakalapudi, 2013).

Siber alan ile fiziksel dünyayı internet ile birbirine bağlayan sistemler siber-fiziksel sistemler (CPS-Cyber-Phsical System) olarak adlandırılmaktadır (Taş, 2018). CPS; bilgi alışverişi, siber dünyada iletişim, fiziksel süreçleri yönetmek, izleyebilmek ve takip edebilme kabiliyeti ile donatılış yazılımlar, ağlar ve bilgisayarlar gibi enformasyon teknolojilerinden oluşmaktadır (Tekin ve Karakuş, 2018). İşletmelerin çoğunluğu hala birbirine bağlı olmayan yönetim ve üretim sistemleri kullanmaktadır. İlerleyen zamanla bağlanırlığın artmasıyla kritik endüstriyel sistemler ve üretim hatlarının siber güvenlik tehditlerine karşı korunma ihtiyacı artacaktır (TÜSİAD, 2016). Siber tehditlere karşı güvenlik standartları ve siber teröre karşı güvenceler daha çok önemli olacaktır (Ambastha, 2017). CPS'ler makinelerin kimliklerini belirleme, makinelere erişimin yönetilmesi, verilerin doğrulanması, sağlıklı şekilde veri transferi ve veri güvenliğini sağlayacaklardır (TÜSİAD, 2016; Bulut ve Akçacı, 2017).

$\mathrm{CC}$, bilgi işlem sistemlerini tasarlama, uygulama geliştirme ve yazılım oluşturma için mevcut hizmetlerden yararlanma şekline odaklanan teknolojik bir gelişmedir. Yalnızca hizmetlere değil, aynı zamanda genel olarak yetenek, depolama, ağ ve bilgi teknolojisi altyapısını hesaplamak için de uygulanan internete dayanan dinamik bir kavramı vurgulamaktadır (Buyya, Vecchiola ve Selvi, 2013). CC hizmetleri verimliliği artırmak, iletişimi geliştirmek, hammadde gereksinimlerinin önceliklendirmek, fabrika verimliliğini ve zamanında üretimi artırmak, her aşamada israfın azaltılması, aşırı siparişi durdurma, el yazısı notlarını ve excel hatalarını kaldırma, malzeme envanteri ve devam etmekte olan işlerin kontrol edilmesi ve azaltılması, zamanında teslimatın iyileştirilmesi gibi konularda yardımcı olmaktadır (Dsouza, 2016). Fabrika bölümü ortamının sıcaklık ve nem gibi parametreleri doğrudan kumaş kalitesini etkiler. Bu gibi etmenler, tüm alanları kapsayan bölüme yerleştirilen uygun sensörler ile ölçülebilir ve bu parametre değerlerini internet üzerinden bulut verilerine paylaşılabilir. Toplanan veriler daha sonra görselleştirilebilir ve kontrol amaçlı kullanılabilir. Ekipman bakımı, çalışma saatleri, sıcaklık gibi çalışma verileri, gerçek zamanlı olarak bulut verileriyle senkronize edilebilir. Böylece koşullu bakım ve makineler için koruyucu bakım tetiklenebilir (Fatiya, 2017). Özellikle hazır giyim endüstrisinde özel tasarlanmış internet tabanlı teknoloji sistemleri sayesinde üretim planlama, hammadde yönetimi, maliyetlendirme, siparişlerin işlenmesi, örnekleme, siparişin hazırlanmasının izlenmesi ve ürünün son teslim edilmesi gibi birçok fonksiyonun basit ve kolay çalışmasını sağlayamamaktadır (Fibre2Fashion.com, 2019). Endüstri 4.0 teknolojisi olan CC’nin yeniden yapılandırılması süreçleri işletmenin büyüklüğüne, coğrafi konumuna ve ticari faaliyet sektörüne ve karar vericilerin tercihlerine bağlı olarak değişebilir. Burada, işletmelerin seçebilecekleri çok sayıda bulut bilişim modeli ve mimarisi olduğunun bilinmesi fayda sağlayacaktır (Ionescu, Bendovschi ve Prichici, 2015). CC hizmeti ve dağıtım modellerinin sunduğu teknoloji ve mimariye örnek olarak, tekstil siparişi süreç yönetim sistemi (TPMS) gösterilebilir (Yang, Liu, Wu, Yang ve Meng, 2011).

Simülasyon teknolojileri ürünün tasarımından üretimine kadar olan tüm süreçlerin önceden simüle edilerek ürünün geleceği ile ilgili bilgilerin önceden alınabilmesi (oluşabilecek hatalar gibi) ve projeksiyonlar üzerinden daha doğru kararlar verilebilmesini sağlar (Mentoro Platformu, 2019). Tekstilde giysi simülasyon sistemi, üç boyutlu giysinin, giysiyi oluşturan 
panellerden yapılandırılmasına olanak sağlayan, bilgisayar destekli tasarım sistemleri, moda tasarım programları, yeni jenerasyon filmler ve bilgisayar oyunları ile gerçekçi simülasyonlar içeren sistemlerdir. Giysi simülasyonunun eğlence sektörü, $\mathrm{CAD} / \mathrm{CAM}$ sistemleri tekstil endüstrisi ve e-ticaret gibi uygulama alanları mevcuttur. Giysilerin 3 boyutlu davranışlarını simule etmek için giysi panelleri 2 boyutlu görünümden 3 boyutlu hale getirilerek paneller sanal bedene üzerine oturtulur. Kullanıcı canlandırma seçenekleri üzerinde değişiklikler yapabilir ve giysinin nasıl daha güzel görünmesi gerektiği belirlenebilir.

\section{MATERYAL VE YÖNTEM}

Bu araştırmanın amacı, Türkiye'deki tekstil işletmelerinin Endüstri 4.0'a adaptasyonunu incelemektir. Bu amaca ulaşabilmek için İSO’nun ilk 500 büyük işletme sıralamasına 2017 ve 2018 yıllarında girmeyi başarmış 115 Tekstil işletmesi, araştırmanın ana kütlesi olarak belirlenmiştir. Araştırmada veri elde etmek için anket yöntemi seçilmiştir. Anket, literatür taraması ve işletme yöneticileriyle yapılan görüşmelerden elde edilen verilerden yararlanarak tasarlanmıştır. Ankete ait yapılan güvenirlik analizinde cronbach alfa değeri 0,736 olarak hesaplanmış ve anketin güvenilir olduğuna karar verilmiştir (Literatürde croncach alfa değeri 0,60 ve üzeri için anketin güvenilir olduğu kabul edilmektedir.) İlgili anket üç kısımdan oluşmaktadır. Birinci kısımda; anketi dolduran kişi ve işletmesi hakkında 8 adet soru bulunmaktadır. İkinci kısımda; Endüstri 4.0'a yatırım yapmayan işletmelerin, Endüstri 4.0'a gelecekte yatırım yapma planlarıyla ilgili 1 adet soru ve işletmelerin Endüstri 4.0'a yatırım yapmama nedenlerini ölçen 13 sorudan oluşan 5'li Likert Ölçek bulunmaktadır. Anketin son kısmında ise; 14 adet sorudan oluşan işletmelerin Endüstri 4.0'a yatırım yapma nedenlerini gösteren 5'li Likert Ölçek ve Endüstri 4.0'ın kullanımının işletme performansına etkisini ölçen 9 adet sorudan oluşan 5'li Likert Ölçek bulunmaktadır.

Anketin işletmelere uygulanması birkaç safhada gerçekleştirilmiştir. Tasarlanan anket, www.surveey.com'da yayınlanmıştır. Öncelikle işletmelerin resmi web sayfaları ziyaret edilmiş ve iletişim bilgilerine ulaşılmıştır. İkinci safhada, işletmelerin resmi web sayfalarından ulaşılan e-postalarına, anketi tanıtıcı bilgi ve anket linki gönderilmiş ve geri dönüşler beklenmiştir. Üçüncü safhada işletmeler telefonla aranarak ilgili kişilere ulaşı1mış ve bu kişilere anket linki gönderilmiştir. Sonuç olarak araştırmanın ana kütlesini oluşturan 115 işletmenin 67'sine $(\% 58,26)$ anket uygulanmış olup, ilgili anketlerden elde edilen veriler bulgular ve tartışma bölümünde verilmiştir.

\section{BULGULAR VE TARTIŞMA}

Çalışmadan elde edilen bulgular kısmının ilk bölümünde anketi cevaplayan kişilerin ve firmalarının demografik özellikleri verilmiştir. Buna göre Tablo 1anket çalışmasına katılan kişilerin işletmelerindeki pozisyonlarını göstermektedir.

Tablo 1

\begin{tabular}{lcc} 
Anketi Cevaplayanların İşletmelerindeki Pozisyonu & & \\
\hline Bölüm (Pozisyon) & Frekans & $\mathbf{\%}$ \\
\hline Ar-Ge (Müdür, uzman, mühendis, destek personeli) & 25 & 39.06 \\
Üretim (Müdür, şef, sorumlu) & 12 & 18.75 \\
İdari Yönetim (Genel müdür, işletme müdürü, genel müdür yrd, icra kurulu üyesi) & 7 & 10.93 \\
Ür-Ge (Mühendis, sorumlu) & 4 & 6.25 \\
Kalite (Müdür, mühendis) & 4 & 6.25 \\
Terbiye Boya-Apre (Müdür, mühendis) & 3 & 4.68 \\
Bilgi Teknolojileri (Müdür, şef) & 2 & 3.13 \\
Satınalma (Müdür, müdür yrd) & 2 & 3.13 \\
İK (Müdür, şef) & 2 & 3.13 \\
Pazarlama (Müdür, Direktör) & 2 & 3.13 \\
Bakım-onarım (Mühendis) & 1 & 1.56 \\
\hline
\end{tabular}

Tablo 1'deki, cevaplayıcıların işletmedeki pozisyonuyla ilgili soruya 67 cevaplayıcıdan 64'ü cevap vermiş̧ir. Cevaplayanların işletmedeki pozisyonları incelendiğinde; 25 (\%39.06) cevaplayıcı Ar-Ge bölümünde; müdür, uzman, mühendis, destek personeli, $12(\% 18,75)$ cevaplayıcı üretim bölümünde; müdür, şef ve sorumlu ve $7(\% 10,93)$ cevaplayıcının ise işletmelerin idari birimlerinde görevli olduğu görülmektedir. Tablo 2'de ise ankete katılan işletmelerin faaliyette bulundukları alt sektörler verilmektedir. 
Tablo 2

İsletmelerin Faaliyette Bulunduğu Alt Sektörler

\begin{tabular}{lcc}
\hline Alt Sektör & Frekans & $\mathbf{\%}$ \\
\hline İplik & 44 & 18.41 \\
Dokuma & 41 & 17.15 \\
Boyama & 41 & 17.15 \\
Apre & 37 & 15.48 \\
Örme & 24 & 10.04 \\
Bask1 & 21 & 8.79 \\
Diğer & 16 & 6.69 \\
Ev Tekstili & 13 & 5.44 \\
Nonwoven & 2 & 0.84 \\
\hline
\end{tabular}

Ankete katılan işletmeler Tablo 2'de yer alan alt sektörlerin birkaçında da faaliyet göstermektedir. Buna göre tablo incelendiğinde, işletmelerin \%68'inin iplik, dokuma, boyama ve apre alt sektörlerinde faaliyet gösterdiği görülmektedir.

Tablo 3

İşletmedeki Toplam Çalışan Sayısı

\begin{tabular}{lcc}
\hline Çalışan Sayısı & Frekans & \% \\
\hline $1-10$ kişi & 0 & 0 \\
$11-49$ kişi & 1 & 1.49 \\
$51-249$ kişi & 4 & 5.97 \\
250 kişi ve daha fazla & 62 & 92.54 \\
\hline
\end{tabular}

Tablo 3'e göre ankete katılan işletmelerin büyük bir çoğunluğu $(\% 92,54) 250$ ve üzerinde çalışana sahiptir. Bu durum, ankete katılan işletmelerin büyük ölçekli olduğunu, belirli bir tecrübe, teknik kabiliyet ve kurumsallığa sahip olduğunu göstermektedir.

Tablo 4

\begin{tabular}{lcc}
$\dot{I}_{\text {Şletme Cirosu }}$ & & \\
\hline Ciro & Frekans & \% \\
\hline 2 Milyon TL'den daha az & 2 & 3.125 \\
2-10 Milyon TL arasında & 2 & 3.125 \\
10-50 Milyon TL arasında & 8 & 12.50 \\
50 Milyon TL'den fazla & 52 & 81.25 \\
\hline
\end{tabular}

Ankete katılan 67 işletmeden ciro bilgisini paylaşan 64 işletmeye ait bilgiler Tablo 4'te verilmiştir. Tablo 4'e göre ankete katılan işletmelerin \%81,25'inin (52 işletme) yıllık 50 Milyon TL'den fazla ciroya sahip olduğu görülmektedir.

\begin{tabular}{lcc} 
Tablo 5 & & \\
Ihracat Yapılan Ülke Sayısı & & \% \\
\hline Ülke Sayısı & Frekans & 1.49 \\
\hline İhracat yapmamaktadır. & 1 & 0 \\
1 Ülke & 0 & 1.49 \\
2 Ülke & 1 & 1.49 \\
3 Ülke & 1 & 2.99 \\
4 Ülke & 2 & 10.45 \\
Ülke & 7 & 2.99 \\
7 Ülke & 2 & 4.48 \\
8 Ülke & 3 & 4.48 \\
9 Ülke & 3 & 0 \\
10 ve üzeri ülke & 0 & 70.14 \\
\hline
\end{tabular}

İşletmelerin ihracat yapmış oldukları ülke sayıları Tablo 5’te verilmiştir. Buna göre, işletmelerin \% 70,14 'ü 10 ve üzeri ülkeye ihracat yapmaktadır. Sadece bir işletmenin ihracat yapmadığ 1 ve yaklaşık \%95'inin en az 4 ülkeye ihracat yaptıkları görülmektedir. 
Tablo 6

Işsletmenin Kullanmakta Olduğu Teknolojiler

\begin{tabular}{lcc}
\hline Teknoloji & Frekans & $\mathbf{\%}$ \\
\hline Robot ve Teknolojileri & 17 & 6.56 \\
3D Tarayıcılar & 2 & 0.77 \\
Eklemeli Üretim Sistemleri (3D Yazıcı) & 2 & 0.77 \\
Artırılmış Gerçeklik (sanal gözlük vb.) & 3 & 1.16 \\
Lazer Kesici Sistemler & 3 & 1.16 \\
Nesnelerin İnterneti & 11 & 4.25 \\
Büyük Veri & 16 & 6.18 \\
Siber Güvenlik Sistemleri & 27 & 10.42 \\
Simülasyon Sistemleri & 5 & 1.93 \\
Bulut Bilişim & 21 & 8.11 \\
Sistemlerin Entegrasyonu & 26 & 10.04 \\
ERP Programları (Kurumsal Kaynak Planlama) & 39 & 15.06 \\
MRP Programları (Malzeme İhtiyaç Planlaması) & 28 & 10.81 \\
CRM Programları (Müşteri İlişkileri Yönetimi) & 21 & 8.11 \\
SCM Tedarik Zinciri Yönetim Programları & 15 & 5.79 \\
CAD / CAM Sistemleri & 23 & 8.88
\end{tabular}

Tablo 6'da işletmelerin kullandığı teknolojiler incelendiğinde \%15.06'lık oranla en fazla ERP programının, sonrasında ERP ile bağlantılı diğer bir program olan MRP'nin (\%10,81), siber güvenlik sistemlerinin (\%10.42) ve sistemlerin entegrasyonu teknolojilerinin (\%10.04) kullandıkları tespit edilmiştir. Tabloye göre, 3D tarayıcıların ve eklemeli üretim sistemlerinin sadece 2 işletmede kullanıldığ görülmektedir.

Tablo 7

Endüstri 4.0 Teknolojilerinin Tekstil Sektörüne Uygulanabilme Durumu

\begin{tabular}{lcc}
\hline Durum & Frekans & \% \\
\hline Uygulanabilir değil. & 2 & 2.99 \\
Çok düşük düzeyde uygulanabilir. & 3 & 4.48 \\
Düşük düzeyde uygulanabilir. & 4 & 5.97 \\
Orta düzeyde uygulanabilir. & 33 & 49.25 \\
Yüksek düzeyde uygulanabilir. & 25 & 37.31 \\
\hline
\end{tabular}

Tablo 7 incelendiğinde, ankete katılan işletme çalışanlarının \%49,25'inin Endüstri 4.0 teknolojilerinin tekstil sektörüne orta düzeyde uygulanabilir olduğunu beyan etmektedir. Aynı zamanda \%37,31’i de bu teknolojilerin tekstil sektörüne yüksek düzeyde uygulanabileceği görüşündeler. Sadece 2 işletme yöneticisinin tekstil sektöründe bu teknolojilerin uygulanabilir olmadığını beyan etmektedir.

Tablo 8

İşletmenin Endüstri 4.0 Teknolojilerine Yatırım Yapma Durumu

\begin{tabular}{lcc}
\hline Yatırım Yapma Durumu & Frekans & \% \\
\hline Evet & 31 & $46.26 \%$ \\
Hayır & 36 & $53.74 \%$ \\
\hline
\end{tabular}

Tablo 8'e göre işletmelerin \%53,74'ünün endüstri 4.0'a yatırım yapmadığı, \%46,26'sının ise yatırım yaptı̆̆ görülmektedir.

Tablo 9

\begin{tabular}{lcc} 
Iş̧letmelerin Endüstri 4.0’a Yatırım Yapma Planı & \\
\hline Yatırım Yapma Planı & Frekans & \% \\
\hline 1-3 yıl içinde Endüstri 4.0 yatırımı yapılacaktır. & 7 & 19.44 \\
4-6 yıl içinde Endüstri 4.0 yatırımı yapılacaktır. & 4 & 11.11 \\
7-9 yıl içinde Endüstri 4.0 yatırımı yapılacaktır. & 2 & 5.56 \\
10-12 yıl içinde Endüstri 4.0 yatırımı yapılacaktır. & 2 & 5.56 \\
13-15 yıl içinde Endüstri 4.0 yatırımı yapılacaktır. & 0 & 0.00 \\
16 yıl ve daha sonra Endüstri 4.0 yatırımı yapılacaktır. & 1 & 2.78 \\
İşletmenin yatırım planında Endüstri 4.0 yer almamaktadır. & 20 & 55.56 \\
\hline
\end{tabular}


Tablo 9'da endüstri 4.0 yatırımı yapmayan işletmelerin gelecek yıllardaki yatırım planları yer almaktadır. Bu tabloya göre, işletmelerin \%55,56'sının (20 işletme) gelecekte Endüstri 4.0’a yatırım yapmayı planlamadıkları görülmektedir. Bu oran, ankete katılan tüm işletmeler (67 işletme) içerinde yaklaşık \%30’luk bir paya sahiptir. Ayrıca işletmelerin yaklaşık \%30'unun da (11 işletme) 1-6 yıl arasında yatırım yapma planlarının olduğu görülmektedir.

Tablo 10

İsletmelerin Endüstri 4.0 Teknolojilerine Yatırım Yapmama Sebepleri

\begin{tabular}{|c|c|c|c|c|c|c|c|c|c|c|}
\hline \multirow[t]{2}{*}{ Yatırım Yapmama Sebebi } & \multicolumn{2}{|c|}{$\begin{array}{c}\text { Hiç } \\
\text { Katılmıyorum }\end{array}$} & \multicolumn{2}{|c|}{ Katılmiyorum } & \multicolumn{2}{|c|}{ Kararsızım } & \multicolumn{2}{|c|}{ Katıliyorum } & \multicolumn{2}{|c|}{$\begin{array}{c}\text { Tamamen } \\
\text { Katılıyorum }\end{array}$} \\
\hline & f & $\%$ & f & $\%$ & f & $\%$ & f & $\%$ & f & $\%$ \\
\hline Endüstri 4.0 hakkında bilgi eksikliği & 2 & 6 & 7 & 19 & 12 & 33 & 7 & 19 & 8 & 22 \\
\hline İşletmeyi geliştirmeye daha fazla odaklanılması & 0 & 0 & 6 & 17 & 8 & 22 & 17 & 47 & 5 & 14 \\
\hline Endüstri 4.0’’n stratejik öneminin henüz anlaşılmamış olması & 1 & 3 & 3 & 8 & 7 & 19 & 14 & 39 & 11 & 31 \\
\hline Endüstri 4.0 için insan kaynağının yetersizliği & 0 & 0 & 2 & 6 & 9 & 25 & 15 & 42 & 10 & 28 \\
\hline Endüstri 4.0, çalışanların sürekli eğitimini gerektirmesi & 3 & 8 & 6 & 17 & 8 & 22 & 11 & 31 & 8 & 22 \\
\hline Endüstri 4.0 ile ilgili standartların olmaması & 3 & 8 & 6 & 17 & 10 & 28 & 11 & 31 & 6 & 17 \\
\hline Endüstri 4.0’’n yatırım maliyetinin yüksekliği & 1 & 3 & 0 & 0 & 7 & 19 & 15 & 42 & 13 & 36 \\
\hline Endüstri 4.0 için teknolojik alt yapının yetersiz olması & 1 & 3 & 1 & 3 & 11 & 31 & 14 & 39 & 9 & 25 \\
\hline Endüstri 4.0 yatırımı için finansal kaynakların yetersiz olması & 4 & 11 & 4 & 11 & 11 & 31 & 9 & 25 & 8 & 22 \\
\hline Endüstri 4.0'ın işletme bilgilerinin çalınmasına neden olacağı endişesi & 6 & 17 & 6 & 17 & 13 & 36 & 7 & 19 & 4 & 11 \\
\hline Endüstri 4.0 için kalifiye insan kaynağının yetersiz olması & 3 & 8 & 3 & 8 & 9 & 25 & 14 & 39 & 7 & 19 \\
\hline Çalışanların Endüstri 4.0 için hazır olmaması & 1 & 3 & 6 & 17 & 6 & 17 & 13 & 36 & 10 & 28 \\
\hline Üst yönetimin Endüstri 4.0’1 öncelikli görmemesi & 0 & 0 & 5 & 14 & 7 & 19 & 11 & 31 & 13 & 36 \\
\hline
\end{tabular}

Tablo 10'a göre, işletmelerin endüstri 4.0 teknolojilerine yatırım yapmama sebepleri incelendiğinde, “Endüstri 4.0’ın yatırım maliyetinin yüksekliğì" (katılıyorum ve kesinlikle katılıyorum yüzdesi beraber ele alındığında-\%78-) ilk sırada yer almaktadır. Daha sonra, Endüstri 4.0’’n stratejik öneminin henüz anlaşılmamış olması (\%69), Endüstri 4.0 için insan kaynağının yetersizliği (\%69) ve üst yönetimin Endüstri 4.0’1 öncelikli görmemesi (\%67) gibi nedenler gelmektedir.

Tablo 11

Işsletmelerin Endüstri 4.0 Teknolojilerine Yatırım Yapma Amaçları

\begin{tabular}{|c|c|c|c|c|c|c|c|c|c|c|}
\hline \multirow[t]{2}{*}{ Yatırım Yapma Amacı } & \multicolumn{2}{|c|}{$\begin{array}{c}\text { Hiç } \\
\text { Katılmıyorum } \\
\end{array}$} & \multicolumn{2}{|c|}{ Katılmıyorum } & \multicolumn{2}{|c|}{ Kararsızım } & \multicolumn{2}{|c|}{ Katılıyorum } & \multicolumn{2}{|c|}{$\begin{array}{c}\text { Tamamen } \\
\text { Katılıyorum }\end{array}$} \\
\hline & f & $\%$ & f & $\%$ & f & $\%$ & f & $\%$ & f & $\%$ \\
\hline Rekabet gücünü artırmak & 1 & 3 & 3 & 10 & 1 & 3 & 8 & 26 & 18 & 58 \\
\hline Verimliliği artırmak & 0 & 0 & 0 & 0 & 0 & 0 & 9 & 29 & 22 & 71 \\
\hline Ürün çeşitliliği artırmak & 3 & 10 & 7 & 23 & 6 & 19 & 9 & 29 & 6 & 19 \\
\hline Yeni pazar firsatları elde etmek & 3 & 10 & 3 & 10 & 7 & 23 & 9 & 29 & 9 & 29 \\
\hline Üretimi tamamen Türkiye de gerçekleştirmek & 4 & 13 & 5 & 16 & 10 & 32 & 8 & 26 & 4 & 13 \\
\hline Rakipleri taklit etmek & 16 & 52 & 9 & 29 & 1 & 3 & 5 & 16 & 0 & 0 \\
\hline Sürdürülebilirliği sağlamak & 0 & 0 & 0 & 0 & 2 & 6 & 10 & 32 & 19 & 61 \\
\hline Müşteri gereksinimini karşılamak & 1 & 3 & 4 & 13 & 4 & 13 & 12 & 39 & 10 & 32 \\
\hline Sektör standartlarına adapte olmak & 0 & 0 & 3 & 10 & 3 & 10 & 15 & 48 & 10 & 32 \\
\hline Maliyetleri düşürmek & 0 & 0 & 0 & 0 & 2 & 6 & 11 & 35 & 18 & 58 \\
\hline Üretimde esneklik kazanmak & 0 & 0 & 0 & 0 & 3 & 10 & 12 & 39 & 16 & 52 \\
\hline Ürün farklılaştırmak & 3 & 10 & 3 & 10 & 6 & 19 & 11 & 35 & 8 & 26 \\
\hline Kaliteyi geliştirmek & 0 & 0 & 0 & 0 & 2 & 6 & 11 & 35 & 18 & 58 \\
\hline İşçilik ihtiyacını azaltmak & 0 & 0 & 1 & 3 & 3 & 10 & 12 & 39 & 15 & 48 \\
\hline
\end{tabular}

Tablo 11'de Endüstri 4.0 teknolojilerine yatırım yapan 31 işletmenin yatırım yapma amaçları incelendiğinde (katılıyorum ve kesinlikle katılıyorum yüzdesi beraber ele alındığında); verimliliği artırmak (\%100) faktörü ilk sırada gelmektedir. Sürdürülebilirliği sağlamak (\%94), maliyetleri düşürmek (\%94), kaliteyi geliştirmek (\%94) ve işçilik ihtiyacını azaltmak (\%87) diğer önemli amaçlar arasında yer almaktadır. Üretimi tamamen Türkiye'de gerçekleştirmek (\%39) ve rakipleri taklit etmek $(\% 16)$ ise yatırım yapma amaçları arasında son sıralarda yer almaktadır. 
Tablo 12

İşletmelerin Endüstri 4.0 Teknolojilerini Kullanım Sonuçları

\begin{tabular}{lccccc}
\hline Sonuçlar & Çok azaldı & Azaldı & Değişmedi & Arttı & Çok arttı \\
\hline Yurt içi satışlar & & & 67.7 & 22.6 & 9.7 \\
Yurt dışı satışlar & & 3.2 & 48.4 & 41.9 & 6.5 \\
Üretim miktarı & & 3.2 & 22.6 & 61.3 & 12.9 \\
Maliyetler & \multirow{2}{*}{6.5} & 54.8 & 12.9 & 22.6 & 3.2 \\
Verimlilik & & 6.5 & 9.7 & 74.2 & 9.7 \\
Karlılık & & & 25.8 & 71.0 & 3.2 \\
Personel Sayısı & & 41.9 & 51.6 & 6.5 & \\
İsraf & 9.7 & 64.5 & 12.9 & 9.7 & 3.2 \\
\hline
\end{tabular}

Tablo 12'de, Endüstri 4.0 teknolojilerini kullanan işletmelerin elde ettikleri sonuçlar verilmektedir. Tabloya göre; işletmelerin \%83,9'unun (Arttı ve Çok arttı) endüstri 4.0 teknolojilerini kullandıktan sonraki elde ettikleri en önemli sonucun verimliliklerindeki artış olduğu görülmektedir. Bunu, üretim miktarlarındaki artış $(\% 74,2)$, karlılıkta artış $(\% 74,2)$ ve israftaki azalmalar (\%74,2) izlemektedir. Ayrıca, ankete katılan işletmelerin \%67,7'sinde Endüstri 4.0 teknolojileri kullanımının yurt içi satışlarında, \%51,6'sinde personel sayısında ve \%48,4’ünde yurt dışı satışlarında değişim olmadığı tespit edilmiştir.

\section{SONUÇ}

Geçmişten günümüze kadar teknoloji sürekli olarak ilerlemekte ve gelecekte de hızlı bir şekilde ilerlemeye devam edecektir. Endüstri 4.0 devriminin bir sonucu olarak ortaya çıkan modern teknolojiler de üretim ortamlarını değiştirmektedir. Bunun sonucu olarak da bilgisayarlar, yazılımlar ve büyük veriler ile donatılmış akıllı cihazlar ve sensörler aktif süreçleri daha iyi bilgilendirerek üreticilerin pazar değiş̧ikliklerine ve tüketici talebine kolaylıkla ayak uydurmalarını sağlamaktadır. Diğer tüm sektörlerde olduğu gibi, tekstil sektöründe de yapay zekâ, makine öğrenmesi, IoT, büyük veri, simülasyon, otomasyon sistemleri, 3D baskı ve daha fazla akıllı teknolojiler etkilerini göstermeye başlamıştır. Tekstil sektörünün geleceğinin yıllar boyunca nasıl olacağını tahmin etmek neredeyse imkansız olmakla birlikte modern teknolojinin benzersiz, uygun maliyetli ve yüksek kaliteli ürünlerin yolunu açacağı kesindir. Bu yüzden, sektör modern teknolojilerin yardımıyla daha dijital odaklı ve daha akıllı süreçlere yönelik olarak şu anda dijital bir dönüşüme doğru ilerlemektedir. Daha fazla özelleştirme firsatı ve daha hızlı pazara sunma süresini sağlayan teknolojiler daha yüksek müşteri memnuniyeti oluşturacaktır.

$\mathrm{Bu}$ çalışmada, Türkiye'deki tekstil işletmelerinin Endüstri 4.0 teknolojilerine olan bakış açılarını, teknolojileri kullanma potansiyellerini ve amaçlarını incelemek amaçlanmıştır. Bu amaca uygun olarak hazırlanan anket, İSO'nun ilk 500 büyük işletme sıralamasına 2017 ve 2018 yıllarında girmeyi başarmış 67 tekstil işletmesine uygulanmış ve elde edilen veriler analiz edilmiştir. Çalışmadan elde edilen sonuçlara göre;

- İşletmelerin en fazla ERP programını kullandıkları tespit edilmiştir. Ancak süreçlerinin verimliliklerini artırarak üretecekleri ürünlerinin daha düşük maliyetli ve daha kaliteli olmalarını sağlamak için ERP ve MRP programlarının yanı sıra daha fazla 3D yazıcı ve tarayıcıları, artırılmış sanal gerçeklik uygulamalarını, IoT ve simülasyon sistemleri gibi teknolojileri kullanmaları gerekmektedir.

- İşletmelerin \%87'si Endüstri 4.0 teknolojilerinin tekstil sektöründe orta ve yüksek düzeyde uygulanabilir olduğunu belirtmişlerdir.

- İşletmelerin \%54’ü endüstri 4.0 teknolojilerine yatırım yapmamıştır. Yatırım yapmayanların yarısından fazlasının da (\%54) gelecekte yatırım planları bulunmamaktadır. Sadece \%38'inin 1-9 yıl arasında yatırım yapma planları bulunmaktadır.

- Endüstri 4.0 teknolojilerinin yatırım maliyetlerinin yüksek olması, insan kaynağının yetersizliği, endüstri 4.0'ın stratejik öneminin henüz anlaşılmaması ve üst yönetimin endüstri 4.0'ı öncelikli görmemesi gibi faktörler, endüstri 4.0 teknolojilerinin tekstil sektöründe uygulanabilir olduğunu savunan işletme yöneticilerinin gelecekte yatırım yapmamalarında etkili olmaktadır.

- İşletmelerin öncelikle verimliliklerini artırmak, maliyetleri düşürmek, sürdürülebilirliği sağlamak, kaliteyi geliştirmek ve işçilik ihtiyacını azaltmak için Endüstri 4.0 teknolojilerine yatırım yaptığı tespit edilmiştir. 
- Endüstri 4.0 teknolojilerini kullanan işletmelerin en fazla verimliliklerinde ve üretim miktarlarında artış, maliyetlerde ve israflarda ise azalma sağladıkları ortaya çıkmıştır.

Çalışmadan elde edilen bu sonuçlara göre halihazırda endüstri 4.0 teknolojilerine mesafeli duran ve yatırım yapmayan işletmelerin hızla gelişen teknolojiler karşısında zorluklar yaşayacaklarının farkında olmaları ve üretim maliyetini düşürmek, üretim verimliliğini artırmak, endüstriyel büyümeyi teşvik etmek, işgücü yapısını değiştirmek ve nihayetinde şirketin ve bölgenin rekabet gücünü değiştirmek için daha fazla Endüstri 4.0 teknolojilerini kullanmaları gerekmektedir.

Hakem Değerlendirmesi: Dış bağımsız.

Çıkar Çatışması: Yazarlar çıkar çatışması etmemişlerdir.

Finansal Destek: Yazarlar bu çalışma için finansal destek almadığını beyan etmemişlerdir.

Yazar Katkıları: Çalışma Konsepti/Tasarım- A.Ö., A.Y., M.A.A.; Veri Toplama- A.Ö., M.A.A.; Veri Analizi/Yorumlama- A.Ö., A.Y., M.A.A.; Yazı Taslağı- A.Ö., A.Y.; İçeriğin Eleştirel İncelemesi- A.Ö., A.Y., M.A.A.; Son Onay ve Sorumluluk- A.Ö., A.Y., M.A.A.

Peer-review: Externally peer-reviewed.

Conflict of Interest: The authors have no conflict of interest to declare.

Grant Support: The authors declared that this study has received no financial support.

Author Contributions: Conception/Design of Study- A.Ö., A.Y., M.A.A.; Data Acquisition- A.Ö., M.A.A.; Data Analysis/Interpretation- A.Ö., A.Y., M.A.A.; Drafting ManuscriptA.Ö., A.Y.; Critical Revision of Manuscript- A.Ö., A.Y., M.A.A.; Final Approval and Accountability- A.Ö., A.Y., M.A.A.

\section{Kaynaklar/References}

Abtahi, M., Gyllinsky, J. V., Paesang, B., Barlow, S., Constant, M., Gomes, N., \& Mankodiya, K. (2018). MagicSox: An E-textile IoT system to quantify gait abnormalities. Smart Health, 5, 4-14.

Adanur, S., \& Vakalapudi, J. S. (2013). Woven fabric design and analysis in 3D virtual reality. Part 1: computer aided design and modeling of interlaced structures. Journal of the Textile Institute, 104(7), 715-723.

Allerkamp, D. (2010). Tactile perception of textiles in a virtual-reality system (Vol. 10). Springer Science \& Business Media.

Amoroso, D., \& Tamburrini, G. (2019). I sistemi robotici ad autonomia crescente tra etica e diritto: quale ruolo per il controllo umano?, BioLaw Journal - Rivista di BioDiritto, 1, 34-51.

ATSO. (2017). Antalya firmalarına yönelik endüstri 4.0 durum tespiti ölçeğin geliştirilmesi ve pilot uygulama projesi, Kasım, 20.

Awazade, S. (2017). IoT in intelligent mobile health monitoring system by smart textile. Textile Mates: Your All Time Partner, 11.

Bulut, E. ve Akçacı, T. (2017). Endüstri 4.0 ve inovasyon göstergeleri kapsamında Türkiye analizi. ASSAM Uluslararası Hakemli Dergi, 4(7), 55-77.

Buyya, R., Vecchiola, C., \& Selvi, S. T. (2013). Mastering cloud computing: foundations and applications programming. Elsevier, Waltham, USA.

Chen, Z., \& Xing, M. (2015, September). Upgrading of textile manufacturing based on Industry 4.0. In 5th International Conference on Advanced Design and Manufacturing Engineering. Atlantis Press.

Dsouza H, (2016). Cloud computing makes fashion scm easier. Erişim adresi: https://www.textileexcellence.com/news/fashion-and-lifestyle/cloudcomputing-makes-fashion-scm-easier. (Erişim Tarihi: 30.01.2020).

EBSO, (2017). Sanayi 4.0. Gözden Geçirilmiş İkinci Baskı. İzmir: Araştırma Müdürlüğü.

Fatiya, A. (2017). Role of IoT and digital technology in textile industry. CİO Review, Erişim adresi: https://www.cioreviewindia.com/magazines/textileand-apparel-technology-special-july-2017. (Erişim Tarihi: 15.02.2020).

Fernández-Caramés, T. M., \& Fraga-Lamas, P. (2018). Towards the Internet of smart clothing: A review on IoT wearables and garments for creating intelligent connected e-textiles. Electronics, 7(12), 405.

Fibre2Fashion.com, (2019). Cloud computing in textiles. Erişim adresi: https://www.fibre2fashion.com/industry-article/6906/cloud-computing-in-textiles. (Erişim Tarihi: 02.04.2019).

Hillard, F. (2017). Industrie 4.0 in der deutschen Textilindustrie. Erişim adresi: https://www.i40-magazin.de/news-und-normen/industrie-4-0-in-derdeutschen-textilindustriearbeit-und-konsumenten-veraendern-sich. (Erişim Tarihi: 06.02.2019).

IEC, (2015). Factory of the future. Geneva: white paper. Erişim adresi: https://www.iec.ch/whitepaper/pdf/iecWP-futurefactory-LR-en.pdf. (Erişim Tarihi: 05.06.2019).

Insights, V. (2018). Textile industry anticipating big revolution with data visualization \& analytics. Erişim adresi: https://visualrsoftware.com/textileindustry-data-visualization. (Erişim Tarihi: 12.01.2020).

Ionescu, B. S., Bendovschi, A. C., \& Prichici, C. (2015). Optimising textile industry processes using cloud computing technology/Optimizarea proceselor specifice industriel textile utilizând tehnologia cloud computing. Industria Textila, 66(4), 218.

Jain, S., Bruniaux, J., Zeng, X., \& Bruniaux, P. (2017, October). Big data in fashion industry. In IOP Conference Series: Materials Science and Engineering (Vol. 254, No. 15, p. 152005). IOP Publishing.

Kagermann, H. (2015). Industrie 4.0: Interview with Prof. Henning Kagermann. Erişim adresi: https://engineered.thyssenkrupp.com/en/industrie-4-0interview-mit-prof-henning-kagermann. (Erişim Tarihi:06.02.2019). 
Kagermann, H., Anderl, R., Gausemeier, J., Schuh, G., \& Wahlster, W. (Eds.). (2016). Industrie 4.0 in a Global Context: strategies for cooperating with international partners. Herbert Utz Verlag.

Lomov, S. V., Mikolanda, T., Kosek, M., \& Verpoest, I. (2007). Model of internal geometry of textile fabrics: Data structure and virtual reality implementation. Journal of the Textile Institute, 98(1), 1-13.

Magnenat-Thalmann, N., \& Bonanni, U. (2006). Haptics in virtual reality and multimedia. IEEE MultiMedia, 13(3), 6-11.

Melanson, T. (2018). What industry 4.0 means for manufacturers. Erişim adresi: https://aethon.com/mobile-robots-and-industry4-0. (Erişim Tarihi: 01.02.2020).

Mentoro Platformu. (2019). Türkiye tekstil sektörünün endüstri 4.0 durumu değerlendirmesi ve yol haritası. İstanbul: Türkiye Tekstil Sanayii İşverenleri Sendikası. Erişim adresi: https://www.mentoroplatform.com/turkiye-tekstil-sektorunun-endustri-4-0-durum-degerlendirmesi-ve-yol-haritasi. (Erişim Tarihi: 11.12.2019).

Mikolanda, T., Lomov, S., Kosek, M., \& Verpoest, I. (2004, March). Simple use of virtual reality for effective visualization of textile material internal structures. In CODATA Prague Workshop, Praha (pp. 23-27).

Mrugalska, B., \& Wyrwicka, M. K. (2017). Towards lean production in industry 4.0. Procedia engineering, 182, 466-473.

Özbek, A., \& Yildiz, A. (2020). Digital supplier selection for a garment business using interval type-2 fuzzy topsis. Textile and Apparel, $30(1), 61-72$.

Schwab, K. (2017). The fourth industrial revolution. (S. Talay, Dü., Z. Dicleli, Çev.) İstanbul: Optimist.

Şehgal, K. (2017). SpinTales: These rugs and duvets use augmented reality to keep kids engaged. Erişim adresi: https:/techseen.com/2017/02/16/tataelxsi-welspun-spintales-augmented-reality. (Erişim Tarihi: 06.08.2019).

Simonis, K., Gloy, Y. S., \& Gries, T. (2016, July). Industrie 4.0-automation in weft knitting technology. In IOP Conference Series: Materials Science and Engineering (Vol. 141, No. 1, p. 012014). IOP Publishing.

Tekin, Z. ve Karakuş, K. (2018). Gelenekselden akıllı üretime spor Endüstrisi 4.0. Itobiad: Journal of the Human \& Social Science Researches, 7(3).

TÜSİAD, (2016, February 05). Sanayi 4.0. Erişim adresi: https://www.tusiad.org/indir/2016/sanayi-40.pdf. (Erişim Tarihi:05.02.2020).

Valtas, A., \& Sun, D. (2016). 3D printing for garments production: An exploratory study. Journal of Fashion Technology \& Textile Engineering, 4(3), 1-4.

Xu, L. D., Xu, E. L., \& Li, L. (2018). Industry 4.0: state of the art and future trends. International Journal of Production Research, 56(8), $2941-2962$.

Yang, C., Liu, S., Wu, L., Yang, C., \& Meng, X. (2011). The Application of cloud computing in textile-order service. International Journal of Digital Content Technology and its Applications, 5(8).

Yıldız, A. (2018). Endüstri 4.0 ve akı1lı fabrikalar. Sakarya Üniversitesi Fen Bilimleri Enstitüsü Dergisi, 22(2), 546-556. 
